\title{
Physics of Be Stars
}

\section{Edited by}

ARNE SLETTEBAK

THEODORE P.SNOW
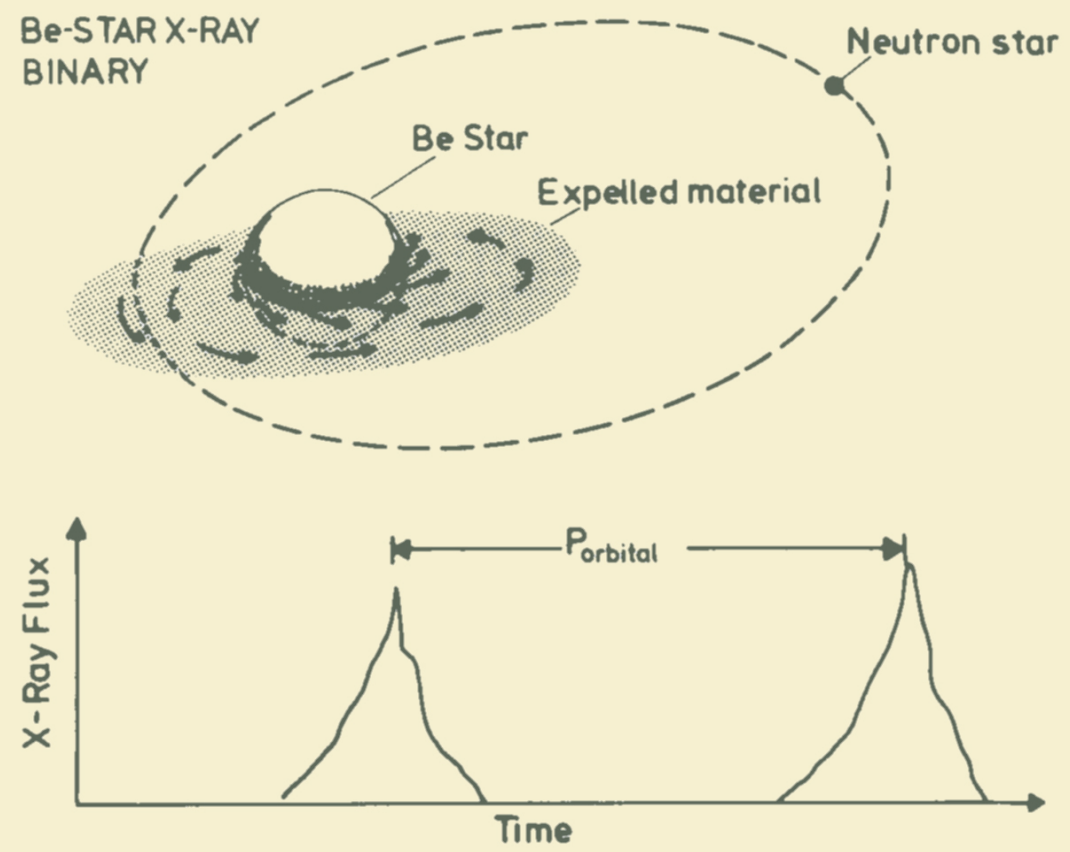
Physics of Be Stars 


\section{Physics of Be Stars}

Proceedings of the 92nd Colloquium of the International Astronomical Union,

Boulder, Colorado 18-22 August 1986

Edited by

ARNE SLETTEBAK

Perkins Observatory

Ohio State and Ohio Wesleyan Universities

Delaware, Ohio

THEODORE P. SNOW

Center for Astrophysics and Space Astronomy

University of Colorado

Boulder, Colorado

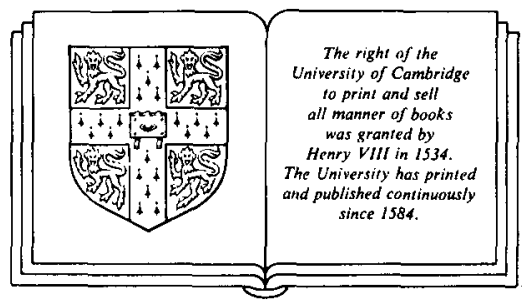

CAMBRIDGE UNIVERSITY PRESS

Cambridge

New York New Rochelle

Melbourne Sydney 
Published by the Press Syndicate of the University of Cambridge

The Pitt Building, Trumpington Street, Cambridge CB2 1RP

32 East 57th Street, New York, NY 10022, USA

10 Stamford Road, Oakleigh, Melbourne 3166, Australia

(C) Cambridge University Press 1987

First published 1987

Printed in Great Britain at the University Press, Cambridge

British Library cataloguing in publication data

International Astronomical Union.

(Colloquium : 92nd : 1986 : Boulder)

Physics of Be stars: proceedings of

the 92nd Colloquium of the International

Astronomical Union, Boulder, Colorado,

18-22 August, 1986.

1. Be Stars

I. Title II. Slettebak, Arne III. Snow,

Theodore $P$.

523.8'44 QB843.B12

Library of Congress Cataloguing in Publication data

International Astronomical Union. Colloquium (92nd :

1986 : Boulder, Colo.)

Physics of Be stars

Sponsored by Commissions 29 (Stellar Spectra) and 45

(Stellar Classification) of the IAU.

1. Be stars-Congresses. I. Slettebak, Arne.

II. Snow, Theodore P. (Theodore Peck) III. International Astronomical Union.

Commission 29. IV. International Astronomical Union.

Commission 45. V. Title.

QB843.B12158 $1986 \quad 523.8^{\prime} 7 \quad 87-855$

ISBN 0521330785 


\section{TABLE OF CONTENTS}

Preface

xii

Organizing Committees

xiv

List of Participants

\section{DEFINITIONS AND TERMINOLOGY}

The Use of Terms and Definitions in the Study of Be Stars

(Review Paper)

$$
\text { G. W. COLLINS II }
$$

IIA. THE UNDERLYING STARS: OBSERVATIONS

Fundamental Parameters of the Underlying Be Stars (Review Paper)

$$
\text { A. SLETTEBAK }
$$

Magnetic Fields in Be Stars? (Review Paper)

P. K. BARKER

Observations of Rapid Variability in Be Stars (Review Paper)

J. R. PERCY

First Measurements of $\gamma$ Cassiopeae's Hydrogen Envelope

P. GRANES, C. THOM, and F. VAKILI

Differential Rotation in $B$ and Be Stars

J. ZOREC, L. DIVAN, R. MOCHKOVITCH, and A. GARCIA 68

About the Spectral Classification of Be Stars

A. FEINSTEIN and H. TIGNANELLI

Short Term Photometric and Spectroscopic Variability of a Sample of Be Stars

M. ALVAREZ and R. MICHEL

Is HR 9070 Really Pulsating?

J. P. SAREYAN, M. AlVAREZ, J. CHAUVILle,

J. M. LE CONTEL, R. MICHEL, and D. BALLEREAU

The Magnetic Be Star o Orionis E

C. T. BOLTON, A. W. FULLERTON, D. BOHLENDER,

J. D. LANDSTREET, and D. R. GIES

Simultaneous Spectroscopy and Polarization of Be Stars

D. R. GIES and D. McDAVID 
The Short-Period Photometric Variability of Be Stars

L. A. BALONA and C. A. ENGELBRECHT

Some Important Results from Two Photometric Campaigns on Short

Term Variability in Be Stars

C. R. STAGG

Short-Term Spectroscopic Variations of The Be Star 11 Cam

J. CHAUVILLE, M. ALVAREZ, J. P. SAREYAN,

D. BALLEREAU, and R. MICHEL

A Transient Shock-Wave in the Shell of The Be Star HD 184279

D. BALLEREAU and $J$. CHAUVILLE

Rapid Variations of Shell Line Parameters in $\zeta$ Tau

M. BOSSI, G. GUERRERO, and M. SCARDIA

Photometric and $\mathrm{H} \alpha$ Variability in Some Be Stars

S. CATALANO and G. UMANA

IIB. THE UNDERLYING STARS: THEORY

Rotating Stellar Atmospheres (Review Paper)

J. P. CASSINELLI

Rotating Stellar Interiors (Review Paper)

R. C. SMITH

III. THE CIRCUMSTELLAR GAS

Optical Emission-Line Spectra of Be Stars (Review Paper)

J. DACHS

Spectral Energy Distribution and Interstellar Reddening

(Review Paper)

L. HOUZIAUX and J. MANFROID

Structure of the Envelope of EW Lac in 1971-1984

T. KOGURE and M. SUZUKI

Observational Constraints on Cool Disk Models of Be Stars

A. M. HUBERT, M. FLOQUET, J. CHAUVILLE, and

M. Th. CHAMBON

Double Periodicity in Be Stars

D. CLARKE and P. A. McGALE 
Long-Term Polarization Changes of $88 \mathrm{Her}$

J. ARSENIJEVIC, S. JANKOV, and G. DJURASEVIC

Red and Infrared Photometry of Be Stars

G. C. KILAMBI, P. V. RAO, and M. B. K. SARMA

Spectral Energy Distribution of Be Stars

D. KAISER and R. W. HANUSCHIK

High-Resolution Emission-Line Spectroscopy of Be Stars:

Comparison of $\mathrm{H} \alpha$ and Weak Emission Lines

R. W. HANUSCHIK

Absolute Spectrophotometry of Be Stars

T. STIFF and S. JEFFERS

Interstellar Absorption of Some Be Stars

L. BRIOT and J. ZOREC

An Optical Study of Southern Be Stars

F. GIOVANNELLI, C. ROSSI, and A. A. VITTONE

Infrared Observations of Be Stars (Review Paper)

H. J. G. L. M. LAMERS

Near Infrared Spectra of 103 Bright Be Stars

Y. ANDRILLAT

Near Infrared Spectra of Southern Be Stars

L. PASTORI

An Infrared Study of Southern Be Stars: Ground-Based and IRAS Observations

The Relation Between Mass Loss and Luminosity for Be Stars

L. B. F. M. WATERS, H. J. G. L. M. LAMERS, and

J. COTE

High-Energy Phenomena in Be Stars (Review Paper)

T. P. SNOW

Fe II and Fe III Lines as a Diagnostic of the Physical

Conditions in the Atmospheres of Be Stars

G. B. BARATTA, M. FRIEDJUNG, G. MURATORIO, and

R. VIOTTI

Narrow Absorption Components in the UV Spectra of HD 110432 (B1 IIIe)

R. K. PRINJA and H. F. HENRICHS 
The Evidence for Aspect-Dependent Winds in Be Stars

C. A. GRADY, K. S. BJORKMAN, and T. P. SNOW

IUE Spectra of the Be Star HD 174237

S. P. TARAFDAR

The Flux Distributions of Be Stars in the Far-UV

R. STALIO, R. S. POLIDAN, and G. J. PETERS

Voyager Observations of $\zeta$ Tau

T. E. CARONE and R. S. POLIDAN

Long-Termed Variability in the Far Ultraviolet Flux of Be Stars

G. J. PETERS and R. S. POLIDAN

Short-Term Photometric Variability in Be Stars in the FarUltraviolet -- A Preliminary Report

R. S. POLIDAN and G. J. PETERS

Ubiquitous C IV $1550 \AA$ Variability in B Stars

G. SONNEBORN

HD 166596: A Silicon Star with H $\alpha$ Emission?

R. HIRATA, D. N. DAWANAS, and G. JASNIEWICZ

$\mathrm{X}$-Ray Observations of B-Emission Stars (Review Paper)

E. P. J. VAN DEN HEUVEL and S. RAPPAPORT

The Be/X-Ray System HDE 245770/A0535+26 in an Active Phase

C. BARTOLINI, M. BURGER, E. L. VAN DESSEL,

F. GIOVANNELLI, A. GUARNIERI, C. DE LOORE,

and A. PICCIONI

Emission Line Variability in the Be Star X-Ray Binaries

4U1258-61 and 4V2206+54

R. H. D. CORBET

IV. MODELS

Rotationally-Enhanced Stellar Winds (Review Paper)

J. M. MARLBOROUGH

Emission-Line Stars as Interacting Binaries (Review Paper)

P. HARMANEC

Be Stars as Nonradial Pulsators (Review Paper)

D. BAADE

The Spheroidal/Ellipsoidal, Variable Mass-Loss, Decelerated Be Star Mode1 (Review Paper)

v. DOAZAN 
Magnetic-Loop Model for Be Stars (Review Paper)

A. B. UNDERHILL

Profiles of Emission Lines from Rotating Disks

D. A. BROWN

Discrete Components in $\mathrm{OB}$ and Be Stars: The Shocking Truth?

P. K. BARKER

Consistent Spherical NLTE-Models for Be Stars

P. HOFLICH

A Rotating, Magnetic, Radiation-Driven Wind Model Applied to Be Stars

C. H. POE and D. B. FRIEND

He $I$ Lines in the $\mathrm{Be}+\mathrm{K}$ Binary $\mathrm{KX}$ And

S. STEFL

Ultraviolet Observations of CX Draconis

P. KOUBSKY, J. HORN, P. HARMANEC, G. J. PETERS,

R. S. POLIDAN, and P. K. BARKER

The Far UV Spectrum of Binary System AX Mon

E. DANEZIS

Be Binary Systems with a Cool Companion: Are They Interacting?

M. FLOQUET, A. M. HUBERT, J. P. MAILLARD, and

$\mathrm{J}$. CHAUVILLE

Interacting Binaries as Be Stars

M. J. PLAVEC

Omicron Andromedae Photometry, Polarimetry, and a Tentative

Model of the Light Variability

P. HARMANEC, K. OLAH, H. BOZIC, P. HADRAVA, J. HORN,

P. KOUBSKY, S. KRIZ, N. H. MINIKUNOV, M. MUMINOVIC,

J. R. PERCY, A. G. SKCHERBAKOV, M. STUPAR, and

A. E. TARASOV

Pole-On Cataclysmic Variables as Be Stars

R. F. GARRISON

Non-Radial Pulsations and the Be Phenomenon

G. D. PENROD

Spectral Transients in the Line Profiles of $\lambda$ Eridani

M. A. SMITH, D. R. GIES, and G. D. PENROD 


\section{EVOLUTIONARY STATUS OF Be STARS}

Galactic Distribution, Kinematics, Locations in Clusters and $\mathrm{H}-\mathrm{R}$ Diagrams, and Duplicity of Be Stars (Review Paper)

$$
\text { H. A. } A B T
$$

The Evolution of Rapidly Rotating B Stars (Review Paper)

$$
\text { R. C. SMITH }
$$

Be Stars as Members of Open Clusters

$$
\text { A. FEINSTEIN }
$$

On the Percentage of Be Stars in Galactic Open Clusters

$$
\text { A. REITERMANN, J. KRAUTTER, and B. WOLF }
$$

Variable Be Stars in $h$ and $\chi$ Persei

C. L. WAELKENS, P. LAMPENS, J. CUYPERS,

J. DENOYELLE, D. HEYNDERICKX, F. RUFENER, and $P$. SMEYERS

Observations and Evolutionary Scenario for Be/X-Ray Binaries

G. M. H. J. HABETS

Evolutionary Models for Be X-Ray Binaries

C. DE LOORE and C. H. B. SYBESMA

Effect of Compact Objects Near Be Stars

K. M. V. APPARAO and S. P. TARAFDAR

Synthetic uvby- $\beta$ Photometry of HD 12856 and HD 13890

A. V. TORRES and C. D. GARMANY

She11 Stars in the Geneva Photometric System

B. HAUCK

Spectral Variability of $\beta$ Pictoris and the Search for Nearby Proto-Planetary Systems

F. C. BRUHWEILER and Y. KONDO

A Photometric Study of Herbig Ae/Be Stars

E. E. MENDOZA V.

On the Pulsating Envelope of HD 200775

M. RUUSALEPP 
VI. PANEL DISCUSSION OF FUTURE RESEARCH
Panelists:
G. J. PETERS
T. KOGURE
A. G. HEARN
C. T. BOLTON
H. F. HENRICHS
M. A. SMITH

Moderator: M. J. PLAVEC

Reflections on Be Stars and the Be Phenomenon

M. J. PLAVEC 